\title{
Performance Characterization of Polymer Modified Asphalt Binders and Mixes
}

\author{
Nikhil Saboo and Praveen Kumar \\ Department of Civil Engineering, Indian Institute of Technology, Roorkee 247667, India \\ Correspondence should be addressed to Nikhil Saboo; niks.iitkgp88@gmail.com
}

Received 3 November 2015; Revised 12 January 2016; Accepted 19 January 2016

Academic Editor: Ghassan Chehab

Copyright (C) 2016 N. Saboo and P. Kumar. This is an open access article distributed under the Creative Commons Attribution License, which permits unrestricted use, distribution, and reproduction in any medium, provided the original work is properly cited.

Fatigue sensitivity of four different asphalt binders and three different asphalt mixes was evaluated in the study. Binders were subjected to Linear Amplitude Sweep (LAS) test at three temperatures of 10, 20, and $30^{\circ} \mathrm{C}$. Four-point beam bending test (4PBBT) was conducted on the asphalt mixes at a temperature of $20^{\circ} \mathrm{C}$ for strain amplitudes varying from 200 to 1000 microstrains. Tests like retained Marshall Stability and indirect tensile strength (ITS) were also carried out to judge the mix performance. Experimental studies demonstrated that elastomeric modified binder and mixes gave the best performance in fatigue. Plastomeric modification was found to be highly strain susceptible and resulted in poor fatigue performance. The fatigue life of stone mastic asphalt (SMA) was found to be almost five times higher than the dense graded mixes. For similar strain levels, the results of LAS test could be linearly correlated with the $4 \mathrm{PBBT}$ results.

\section{Introduction}

High stresses due to heavy vehicular loading, increase in temperature, and introduction of new axle configuration demand effective strengthening of pavements. Use of modified binders is among the most common techniques, employed to improve the strength characteristics of bituminous mixes [1-3]. Amid various forms of modification, polymers tend to increase the viscoelastic response of binder and reduce its temperature susceptibility [4-8]. Polymer increases the stiffness of the binder at higher temperature, while upholding flexibility at lower temperatures.

The current superpave specification for performance grading was developed mainly for unmodified binders and has been proved to be misleading for predicting rutting and fatigue properties of modified bitumen [9-13]. The method employs the parameter $\left|G^{*}\right| \cdot \sin \delta$ to quantify the asphalt binder fatigue resistance. $\left|G^{*}\right|$ is the complex shear modulus while $\delta$ is the phase lag between the stress and strain amplitudes. It is based on the concept that lower dissipated energy per loading cycle $\left(\pi \cdot \gamma_{0}{ }^{2} \cdot\left|G^{*}\right| \cdot \sin \delta\right)$ will lead to lower distress accumulation. $\gamma_{0}$ is the strain amplitude for constant strain testing. Hence, the intermediate temperature is determined, such that $\left|G^{*}\right| \cdot \sin \delta$ is less than $5000 \mathrm{kPa}[14]$. This stiffness based parameter, which is a development of Strategic Highway Research Program (SHRP), is measured at a fixed frequency $(10 \mathrm{rad} / \mathrm{sec})$ ensuring the strain to be below the linear viscoelastic regime of the bitumen. The recommended strain value is $1-2 \%$. The test was developed based on the speculation that binder in pavements functions mostly in the linear viscoelastic range and is not likely to affect bitumen's properties. This simple test cannot describe the actual complicated fatigue phenomena in which the binder is exposed to higher strain levels and varied frequency levels.

Fatigue is one of the three (rutting, fatigue cracking, and low temperature cracking) major failure modes in flexible pavements which results in degradation of the pavement materials and finally the pavement structure [15]. The materials in pavement are subjected to short time load amplitudes upon passage of a vehicle. Higher amplitudes of this repeated loading result in reduction of material stiffness and its subsequent accumulation with time may lead to complete failure [16].

Over the past 40 years, different test methods have been developed to simulate the fatigue behavior of hot mix asphalt (HMA) materials, with varying success [17-24]. 
Tangella et al. [25] listed the general categories of different test methodologies which included simple flexure, supported flexure, diametral test, triaxial test, direct axial test, fracture test, and wheel tracking test. In the SHRP-A-404 report [26], a comprehensive evaluation was performed based on which the repeated flexure beam test (third/four-point bending) was given the highest rank. Usually, two types of loading modes are adopted in laboratory fatigue testing: constant stress (controlled-stress) mode and constant strain (controlledstrain) mode. In the constant stress loading mode, the stress is kept constant and the strain increases with load cycles, whereas, in the constant strain mode of loading, the strain is maintained constant in all the loading cycles and the stress decreases subsequently. In the field, the loading conditions are more complex and are usually combined modes of loading [27]. Researchers $[25,28]$ have suggested that controlledstrain testing might be used for relatively thin pavements with HMA less than $50 \mathrm{~mm}$ ( $2 \mathrm{in}$.), because the strain in thin asphalt layer is governed by the underneath layers and is merely affected by the decrease in stiffness of the asphalt mix. The controlled-stress testing might be more appropriate for thicker pavements of more than $152 \mathrm{~mm}$ (6 in.) where the main load-carrying component is the top layer. For intermediate thicknesses, a combination of constant stress and constant strain exists. It has been found that the fatigue life obtained from constant stress testing condition is shorter than the life obtained from constant strain testing condition [26]. In this study, constant strain mode has been adopted assuming that the thickness of the wearing course is not high.

A plethora of studies have indicated the improvement in rheological and mechanical properties of bitumen with addition of polymers $[8,29-31]$. In general, elastomeric modification has been found to improve the lower temperature susceptibility of binders while plastomeric modified binders tend to improve the high temperature properties $[8,32-$ 34]. Few studies also demonstrated the increase in fatigue properties with use of plastomeric modified binders [35]. Specifically, the change in properties are a function of the type and amount of modifier used and also the base chemical properties of the base bitumen. Study on variation of fatigue life with change in strain amplitudes for modified binders is however a new area to be explored.

(1) Objective of the Study. Although studies have reported the fatigue characteristics of different asphalt binders and mixes; very few have focused on correlating and comparing the binders fatigue life using LAS test with the fatigue behavior of asphalt mixes. Since LAS is a new test method, a critical study is required using different binders and checking its validity with the fatigue performance of different asphalt mixes. The main objective of the study is to compare and correlate the fatigue response of different asphalt binders and mixes corresponding to different strain levels.

\section{Materials}

2.1. Bitumen. Four binders were used in the study. VG 10 and VG 30 were the viscosity graded (VG) binder. VG 10 was being modified with elastomeric Styrene Butadiene

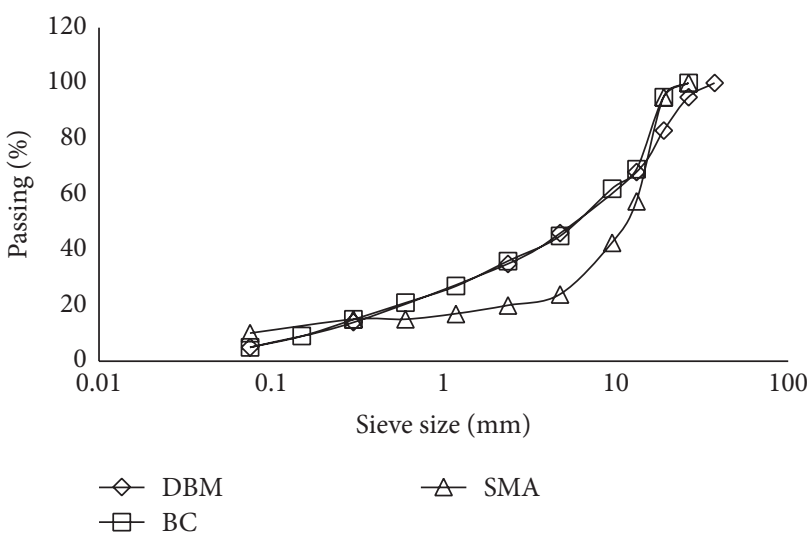

Figure 1: Aggregate gradation adopted in the study.

Styrene (SBS) and plastomeric Ethylene Vinyl Acetate (EVA) at various percent of modification level. An earlier study done by the authors [36] found that the interlocked phase of polymer with the base binder is obtained using 3\% SBS and 5\% EVA. Higher percentages yielded binders which were susceptible to phase separation. Moreover, using lower percentages did not fully optimize the properties of the base binder, which resulted in an uneconomical blend. So, for comparison, only 3\% SBS and 5\% EVA are considered in the study. The conventional properties along with the high temperature performance grade (PG) specification and true intermediate grade temperature for these binders are presented in Table 1. In this paper, the polymer modified bitumen will be represented as PMB (E) and PMB (S) indicating modification with EVA and SBS. The authors also studied the optimum blending requirements for both the polymers. Following the study, PMB (S) was modified at a temperature of $180^{\circ} \mathrm{C}$ using a high shear mixture operated at $1500 \mathrm{rpm}$ for 60 minutes. PMB (E) on the other hand was modified at $190^{\circ} \mathrm{C}$, at a shear rate of $600 \mathrm{rpm}$ for 30 minutes.

2.2. Aggregate. Quartzite aggregates were used and obtained from a local quarry. The conventional properties of aggregates were measured which followed the specifications in accordance with Ministry of Road Transport and Highways (MoRT\&H), India.

2.3. Gradations Adopted. Three gradations were adopted in the study, namely, bituminous concrete (BC), dense bituminous macadam (DBM), and stone mastic asphalt (SMA). The nominal maximum aggregate sizes (NMAS) of $19 \mathrm{~mm}$, $26.5 \mathrm{~mm}$, and $19 \mathrm{~mm}$ were used, respectively. The gradation requirements are as per MoRT\&H. BC and DBM are amongst the dense graded mixes most commonly used in India for the surface and binder courses, respectively. SMA on the other hand is a gap-graded mix used as a wearing course with high rut resistant properties. Usually, SMA is used at places with extreme conditions of temperature and loading. Figure 1 presents the sieve size distribution for the respective mixes. Each type of mix was prepared with all the four binders. For SMA, first, the drain-down test was carried 
TABLE 1: Conventional properties of binders used in the study.

\begin{tabular}{|c|c|c|c|c|c|c|c|}
\hline Binders & $\begin{array}{c}\text { Penetration, } \\
\text { dmm }\end{array}$ & $\begin{array}{l}\text { Softening } \\
\text { point, }{ }^{\circ} \mathrm{C}\end{array}$ & $\begin{array}{l}\text { Penetration } \\
\text { index }\end{array}$ & $\begin{array}{l}\text { Viscosity at } \\
60^{\circ} \mathrm{C}, \mathrm{Pa} \cdot \mathrm{s}\end{array}$ & $\begin{array}{c}\text { Storage } \\
\text { stability, } \\
\Delta \text { Soft. point, } \\
{ }^{\circ} \mathrm{C}\end{array}$ & $\begin{array}{c}\text { High } \\
\text { temperature PG } \\
\text { grade }\end{array}$ & $\begin{array}{c}\text { True grade, } \\
\text { intermediate } \\
\text { temperature, }{ }^{\circ} \mathrm{C}\end{array}$ \\
\hline VG 10 & 75 & 47 & -1.01 & 258 & - & PG 58-XX & 25.3 \\
\hline VG 30 & 62 & 49 & -0.95 & 375 & - & PG 64-XX & 20.1 \\
\hline PMB (S) & 56 & 60 & 1.31 & 2120 & 1.5 & PG 70-XX & 15.7 \\
\hline $\mathrm{PMB}(\mathrm{E})$ & 49 & 65 & 1.92 & 6120 & 1.3 & PG 76-XX & 12.2 \\
\hline
\end{tabular}

TABLE 2: Drain-down test results.

\begin{tabular}{lcc}
\hline Type of mix & Type of binder & $\begin{array}{c}\text { Drain-down }(\%) \\
(\max 0.3)\end{array}$ \\
\hline SMA & VG 10 & 0.57 \\
SMA & VG 30 & 0.43 \\
SMA & PMB (S) & 0.28 \\
SMA & PMB (E) & 0.26 \\
\hline
\end{tabular}

out using all the binders. As SMA is a gap-graded mix, the binders are susceptible to flow out of the mix at high handling temperatures (near about $163^{\circ} \mathrm{C}$ ). This phenomenon is known as drain-down which should be less than $0.3 \%$ as per specification outlined in Indian Roads Congress (IRC) SP79 2008. Drain-down test was carried out using Schellenberg method [37]. It was found that only the modified binders (PMB (S) and PMB (E)) satisfied the maximum drain-down criteria. So VG 10 and VG 30 were not used for preparing SMA samples. Moreover, SMA should have high resistance properties and thus it should have a stiff binder which in this case cannot be VG 10 or VG 30 as shown by the results in Table 1. Table 2 presents the results of the drain-down test.

2.4. Mix Design. All the bituminous mixes in the study were prepared using Marshall Mix design procedure. Samples for $\mathrm{BC}$ and DBM were compacted by applying 75 blows on each face while SMA was compacted through application of 50 blows on each face, respectively. Samples were prepared at five binder contents for each mix type with three identical samples at each binder content. The procedure as recommended by NAPA was used for the determination of the optimum binder content (OBC). According to the method, the binder content corresponding to $4 \%$ air void (by weight of the mix) is determined first and this binder content is used to determine the values of Marshall Stability, voids in mineral aggregates (VMA), flow, and percent voids filled with bitumen (VFB). Each value is compared against the specification value for that property and if all are found to be within the specification range, the asphalt content at 4 percent air void is considered as the optimum. After determination of the OBC corresponding to $4 \%$ air void, three more samples at that binder content were prepared for Marshall testing.

\section{Experimental Investigation}

3.1. Linear Amplitude Sweep (LAS) Test. Linear Amplitude Sweep test following AASHTO TP 101-14 was conducted to determine the parameters $A$ and $B$, to assess the fatigue life of the binders at different strain levels. $A$ and $B$ are the model parameters of the fatigue equation. This test was done at 10,20 , and $30^{\circ} \mathrm{C}$ for all the binders. The results reported in the study are an average of three samples for each temperature. The test requires conducting a frequency sweep test followed by a Linear Amplitude Sweep. The frequency sweep is conducted at a very low strain level of $0.1 \%$ to obtain undamaged material properties, which is used as an input in the analysis of amplitude sweep test. The amplitude sweep test is conducted by linearly varying strain from 0 to $30 \%$, through 3100 loading cycles at a fixed frequency of $10 \mathrm{~Hz}$. The test begins with 100 cycles of sinusoidal loading at $0.1 \%$ strain followed by incremental load steps of 100 cycles each, at a rate of $1 \%$ increment in strain level.

The frequency sweep test $(0.2-30 \mathrm{~Hz})$ is used for the determination of the parameter alpha $(\alpha)$ which is later used in the analysis of strain sweep data. $\alpha$ is the reciprocal of the straight line slope $(m)$ of $\log G^{\prime}(\omega)$ versus $\log \omega$ curve. Frequency sweep is conducted at a strain level of $0.1 \%$, so as to ensure the linear viscoelastic range for the bitumen:

$$
\alpha=\frac{1}{m} .
$$

Amplitude or strain sweep test is conducted at a frequency of $10 \mathrm{~Hz}$, with loading increasing from zero to $30 \%$ over the course of 3100 cycles of loading. The damage accumulation in the specimen is calculated using the formulae [38]:

$$
D(t) \cong \sum_{i=1}^{N}\left[\pi \gamma_{0}^{2}\left(C_{i-1}-C_{i}\right)\right]^{\alpha /(1+\alpha)}\left(t_{i}-t_{i-1}\right)^{1 /(1+\alpha)},
$$

where $C(t)$ is the ratio of $\left|G^{*}\right|(t)$ to $\left|G^{*}\right|_{\text {initial }}$, which are the value of complex shear modulus at any time $t$ and the initial undamaged $\left|G^{*}\right|$.

Further, the calculated $C(t)$ and $D(t)$ are used to fit a relation of the form:

$$
C_{t}=C_{0}-C_{1}(D)^{C_{2}},
$$

where $C_{0}, C_{1}$, and $C_{2}$ are evaluated using curve fitting. $C$ at peak stress is used to calculate the value of $D(t)$ at failure $\left(D_{f}\right)$ using the above equation. 
The binder fatigue life $N_{F}$ is calculated using the equation:

$$
N_{F}=A\left(\gamma_{\max }\right)^{B},
$$

where $A$ and $B$ are the model parameters and are evaluated using the following equations:

$$
\begin{aligned}
& A=\frac{f\left(D_{f}\right)^{k}}{k\left(\pi C_{1} C_{2}\right)^{\alpha}}, \\
& B=2 \alpha .
\end{aligned}
$$

In the above equations, $f$ is the frequency $(10 \mathrm{~Hz})$ and $k$ is calculated as follows:

$$
k=1+\left(1-C_{2}\right) \alpha .
$$

The above method for characterizing the fatigue is generated from the viscoelastic continuum damage (VECD) principle, which starts from the basic Schapery's equation for damage $(D)$ rate, written as [39]

$$
\frac{d D}{d t}=-\frac{\partial W}{\partial D}
$$

The above equation for viscoelastic materials was modified to obey power law based on Paris Law of crack growth:

$$
\frac{d D}{d t}=\left(-\frac{\partial W}{\partial D}\right)^{\alpha} .
$$

$W$ is the materials energy potential, while $\alpha$ is the exponent determining the energy release rate.

Further, the work done by Park and coworkers [39] for monotonic loading was implemented for harmonic loading as typical in flexible pavements. For strain controlled cyclic shear loading, the dissipated energy during each cycle was used in place of $W$ in (8) [12]. The dissipated energy is derived from the work done per unit volume by the material, when subjected to cyclic loading. It could be written as

$$
W=\pi \cdot \gamma_{0}^{2} \cdot\left|G^{*}\right| \cdot \sin \delta .
$$

Using this equation in the above equation yields the solution as

$$
\begin{aligned}
D(t) \cong & \sum_{i=1}^{N}\left[\pi \gamma_{0}^{2}\left(\left|G^{*}\right| \sin \delta_{i-1}-\left|G^{*}\right| \sin \delta_{i}\right)\right]^{\alpha /(1+\alpha)} \\
& \cdot\left(t_{i}-t_{i-1}\right)^{1 /(1+\alpha)} .
\end{aligned}
$$

Further using (3) in (9) will give

$$
\frac{d W}{d D}=-\pi C_{1} C_{2}(D)^{C_{2}-1}\left(\gamma_{\max }\right)^{2} .
$$

Equations (11) and (8) create a differential equation, which on solving will give

$$
\begin{aligned}
D(t)= & {\left[\frac{1}{\left(-\alpha C_{2}+\alpha+1\right) t}\right]^{\left(1 /\left(\alpha C_{2}-\alpha-1\right)\right)} } \\
& \cdot\left[\frac{1}{\left(\pi C_{1} C_{2} \pi^{2}\right)}\right]^{\left(\alpha /\left(\alpha C_{2}-\alpha-1\right)\right)} .
\end{aligned}
$$

This equation is finally transformed to (4).

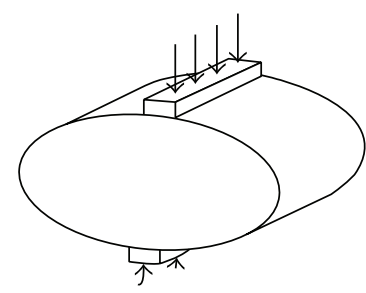

(a) Load configuration

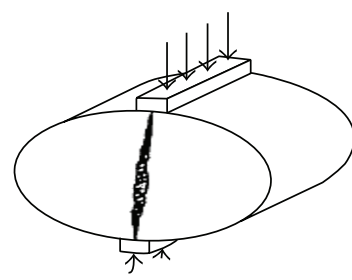

(b) Failure of specimen
FIGURE 2: Indirect tension strength test loading and failure process.

3.2. Moisture Susceptibility Test. The susceptibility of asphalt mixtures to moisture is another measure of the durability. Retained Marshall Stability test was employed for evaluating the sensitivity of the mixes and binders to moisture. Tensile strength ratio (TSR) was also calculated for assessing the moisture susceptibility of bituminous mixes. MoRT\&H requires a minimum of $80 \%$ TSR to make the mix resistive to moisture damage. Marshall Stability of compacted specimens was determined after conditioning them by keeping in water maintained at $60^{\circ} \mathrm{C}$ for $24 \mathrm{~h}$ prior to testing. This stability, expressed as percentage of the stability of Marshall Specimens determined under standard conditions, is the retained stability of the mix. Tensile strength ratio (TSR) is the average static indirect tensile strength of the conditioned specimens expressed as percentage of the average static indirect tensile strength of unconditioned specimens. Conditioning was done by keeping the specimens in water maintained at $60^{\circ} \mathrm{C}$ for $24 \mathrm{~h}$ and by curing at $25^{\circ} \mathrm{C}$ for $2 \mathrm{~h}$ before commencing the test. The test was conducted at $25^{\circ} \mathrm{C}$. Three samples were prepared for checking the consistency in the results and the average value was calculated.

3.3. Indirect Tension Strength (ITS) Test. In the study, ITS test was conducted in accordance with ASTM D 6931, 2012, at $25^{\circ} \mathrm{C}$. Indirect tensile strength test procedure consists of applying a load along cylindrical specimen's diametrical axis at a fixed deformation rate of $5.1 \mathrm{~cm} / \mathrm{min}$ until failure and determining the total vertical load at failure of the specimen at $25^{\circ} \mathrm{C}$. Failure is defined as the point after which there is no increase in load. A nearly uniform tensile stress is developed normal to the direction of the applied load along the same vertical plane causing the specimen to fail by splitting along the vertical diameter. Figure 2 shows the loading and failure phenomena in the test. The maximum load sustained by the specimen is used to calculate the indirect tensile strength using the following expression:

$$
S_{T}=\frac{2 F}{3.14(h d)},
$$

where

$S_{T}$ is indirect tensile strength,

$F$ is total applied vertical load at failure, $\mathrm{N}$,

$h$ is height of specimen, $\mathrm{mm}$,

$d$ is diameter of specimen, $\mathrm{mm}$. 
TABLE 3: Test condition adopted for 4PBB test.

\begin{tabular}{lcc}
\hline S. number & Test parameter & Test condition \\
\hline 1 & Test temperature $\left({ }^{\circ} \mathrm{C}\right)$ & $20 \pm 0.5$ \\
2 & Strain amplitude $\left(10^{-6} \mathrm{~m}\right)$ & $200-1000$ \\
3 & Loading frequency $(\mathrm{Hz})$ & 10 \\
4 & Air void content $(\%)$ & $4 \pm 0.2$ \\
5 & Type of loading & Sinusoidal \\
6 & Failure condition & When the flexural stiffness is reduced to $50 \%$ of \\
& & the initial flexural stiffness or 200000 loading \\
& & cycles have been applied, whichever occurs first. \\
\hline
\end{tabular}

3.4. Four-Point Beam Bending Test (4PBBT). The flexural fatigue testing protocol of AASHTO T321-2003 and SHRP M-009 requires preparation of oversized beam specimens that have to be sawed to the required dimensions. The final required dimensions are $380 \pm 6 \mathrm{~mm}$ ( $15 \pm 1 / 4 \mathrm{in}$.) in length, $50 \pm 6 \mathrm{~mm}(2 \pm 1 / 4 \mathrm{in}$. $)$ in height, and $63 \pm 6 \mathrm{~mm}$ $(2.5 \pm 1 / 4$ in. $)$ in width. No specific procedure is mentioned for beam preparation. However, several methods including full scale rolling wheel compaction, miniature rolling wheel compaction, and vibratory loading have been used over years.

In this study, the beams were prepared adopting a new method of loading and unloading. The mold used for beam preparation had an inside dimension of $382 \mathrm{~mm} \times 50 \mathrm{~mm} \times$ $70 \mathrm{~mm}$. The final dimension was fixed as $382 \mathrm{~mm} \times 50 \mathrm{~mm}$ $\times 50 \mathrm{~mm}$ to achieve uniform beam sizes for all the types of mixtures. All the specimens were prepared to achieve a target air void content of $4 \%$ by weight of the total mix. As the height of beam was fixed, the weight of the mixture required to achieve the target air void was precalculated. The aggregates and bitumen were mixed at the required mixing temperature and was placed in the preheated mold. A compression testing machine was used for applying load till the desired height was reached. The loading was accompanied by an unloading process to avoid breaking of aggregates due to static loading. After compaction, the specimen was allowed to cool for 24 hours. The beam was extracted from the mold and the air void content was measured using the saturated surface-dry procedure (AASHTO T166). Compacting the specimens is one of the most difficult tasks, when the target air void content is fixed. This may be possible but would require many trials. So an allowance of $\pm 0.2 \%$ was given to the required air void content. The testing protocol mentioned in Table 3 was adopted for conducting the four-point beam bending (4PBB) test. Two samples were prepared for each combination of binder and mix.

The maximum tensile stress and strain were calculated using the following equations:

$$
\begin{aligned}
\sigma_{t} & =\frac{0.382 \cdot P}{b \cdot h^{2}}, \\
\varepsilon_{t} & =\frac{12 \cdot \delta \cdot h}{3 \cdot L^{2}-4 \cdot a^{2}},
\end{aligned}
$$

where

$$
\sigma_{t} \text { is maximum tensile stress, } \mathrm{Pa},
$$

$\varepsilon_{t}$ is maximum tensile strain, $\mathrm{m} / \mathrm{m}$,

$P$ is applied load, $\mathrm{N}$,

$b$ is average specimen width, $\mathrm{m}$,

$h$ is average specimen height, $\mathrm{m}$,

$\delta$ is maximum deflection at the center of the beam,

$L$ is length of the specimen, $382 \mathrm{~mm}$,

$a$ is length between the clamps $(L / 3=127.33 \mathrm{~mm})$.

The flexural stiffness, phase angle, dissipated energy, and cumulative dissipated energy are calculated as follows:

$$
\begin{aligned}
S & =\frac{\sigma_{t}}{\varepsilon_{t}}, \\
\phi & =360 \cdot f \cdot s, \\
D & =\pi \cdot \sigma_{t} \cdot \varepsilon_{t} \cdot \sin (\phi), \\
\text { C.D.E } & =\sum_{i=1}^{N} D_{i},
\end{aligned}
$$

where

$$
\begin{aligned}
& S \text { is flexural stiffness, } \mathrm{Pa}, \\
& \phi \text { is phase angle, degrees, } \\
& f \text { is load frequency, } \mathrm{Hz}, \\
& s \text { is time lag, seconds, } \\
& D \text { is dissipated energy per cycle, } \mathrm{J} / \mathrm{m}^{3}, \\
& \text { C.D.E is cumulative dissipated energy, } \mathrm{J} / \mathrm{m}^{3} \text {. }
\end{aligned}
$$

\section{Results and Analysis}

4.1. Fatigue Behavior of Binders. Figure 3 shows the comparison of fatigue lives for all the binders at the three temperatures considered in the study. It can be seen that PMB (S) outperforms all the binders irrespective of any test temperatures. At 10 and $20^{\circ} \mathrm{C}$, for low strain levels, PMB (E) had higher fatigue life than VG 10 and VG 30. As the strain level increased (typically after 10\%), the fatigue life decreased steeply for PMB (E), giving lower values than the conventional binders. This describes the higher strain susceptibility for plastomeric PMB (E). Due to higher stiffness at lower temperature, PMB (E) tends to undergo brittle failure when strained to higher 

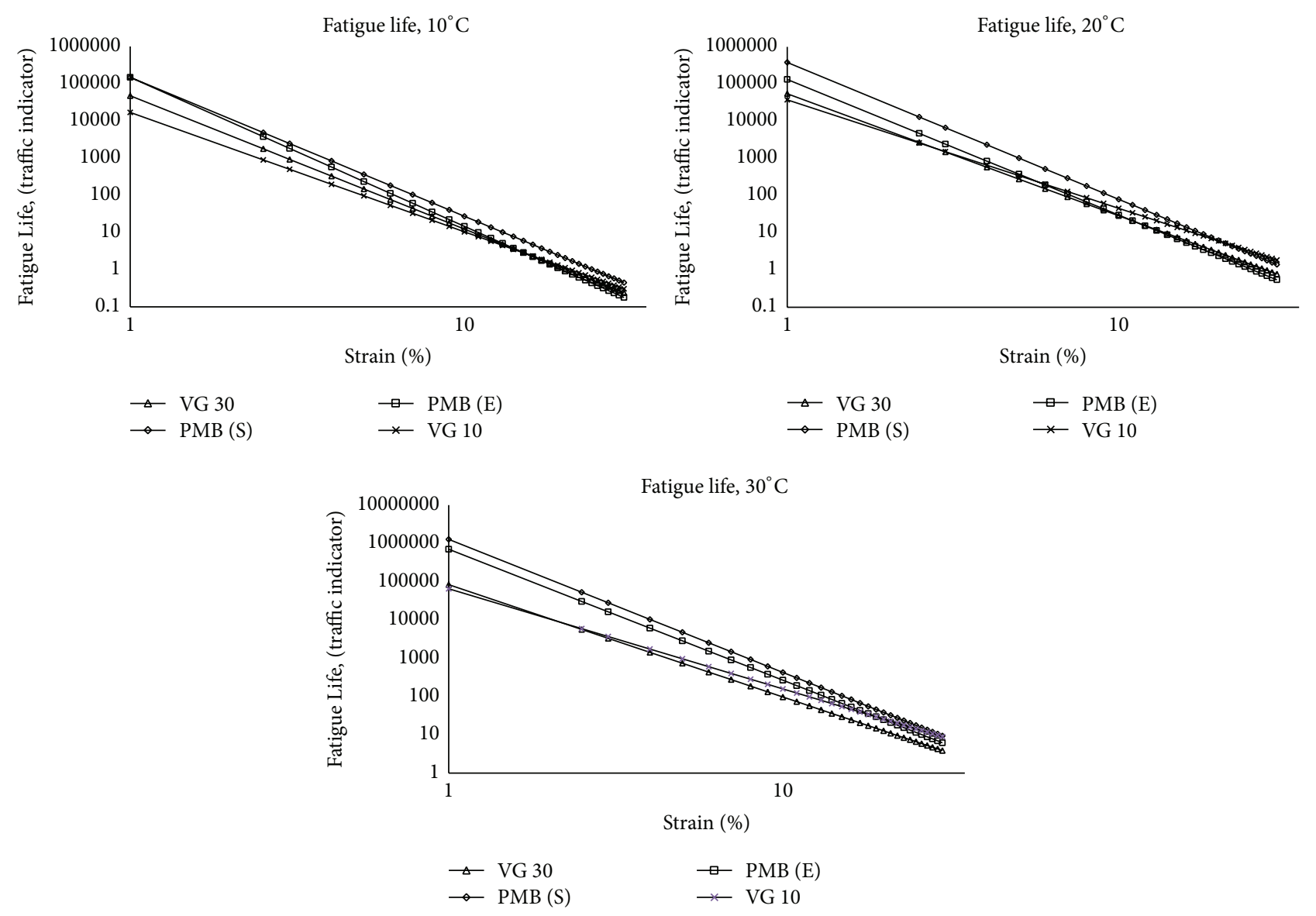

FIGURE 3: Variation of fatigue life at different temperatures.

amplitudes. This is attributed to the crystalline nature of the polyethylene segment in EVA, which imparts brittle nature to the binder at lower temperatures. However, at $30^{\circ} \mathrm{C}$, the fatigue life of PMB (E) was found to be higher than VG 30. It is hence recommended that plastomeric modified binders such as EVA should not be used at regions with lower pavement temperatures and heavily stressed areas. The conventional binders displayed interesting behavior. VG 10 and VG 30 had lower fatigue lives at lower strain amplitudes. But the rate of decrease in fatigue life with increase in strain level was lower than the modified binders. VG 10 had the lowest strain susceptibility and gave better results than PMB (E) and VG 30 at higher strain amplitudes. This phenomenon was compounded in the traditional method of determining fatigue life. As can be seen in Table 1, the true intermediate temperature, for $\left|G^{*}\right| \cdot \sin \delta$ to be lower than $5000 \mathrm{kPa}$, is the lowest for PMB (E), indicating that it would perform better than all other binders. This is contrary to the ranking of binder as demonstrated by LAS test results. Moreover, in the traditional method, the wide spectrum of fatigue behavior with change in strain level cannot be evaluated. Hence, LAS test is a better way of judging the relative fatigue performance of different binders. A statistical test was carried out to see if the data obtained using LAS test for different combination of temperature and strain levels were significantly different.
It was found that the $F$ statistics values $(6.97,3.65$, and 3.35) were higher than the $F$ critical value (1.59) at all the temperatures $\left(10,20\right.$, and $\left.30^{\circ} \mathrm{C}\right)$ at different strain levels (1-30\%) which indicates that the results are significantly different. The tables are not presented in this paper for brevity.

The fatigue life for all the binders using LAS method was found to be sensible to the value of $\alpha$ and $A$. A lower value of $\alpha$ and a higher value of $A$ are desirable for superior performance in fatigue. " $\alpha$ " indicates the rate of reduction in fatigue life with increase in strain amplitude. A lower value would indicate lower strain susceptibility. In general, $\alpha$ decreases and $A$ increases with increase in temperature for all the binders. But the change in the respective values with change in temperature is different for each binder. Also, it is observed that the value of $\alpha$ has dependence on the stiffness of binder. The value increased with increase in stiffness, with PMB (E) having the highest value. Table 4 presents the values of the $A$ and $\alpha$ at all the test temperatures.

Variation of fatigue life with temperature was also evaluated corresponding to two different strain levels as can be seen in Figure 4. Usually, it is assumed that the strain in the binder is about 50 times that in the mixture [40]. Hence, the fatigue life at two strain levels was evaluated for comparison. $2.5 \%$ and $5 \%$ corresponding to 500 microstrains and 1000 microstrains were reported. In general, the fatigue 

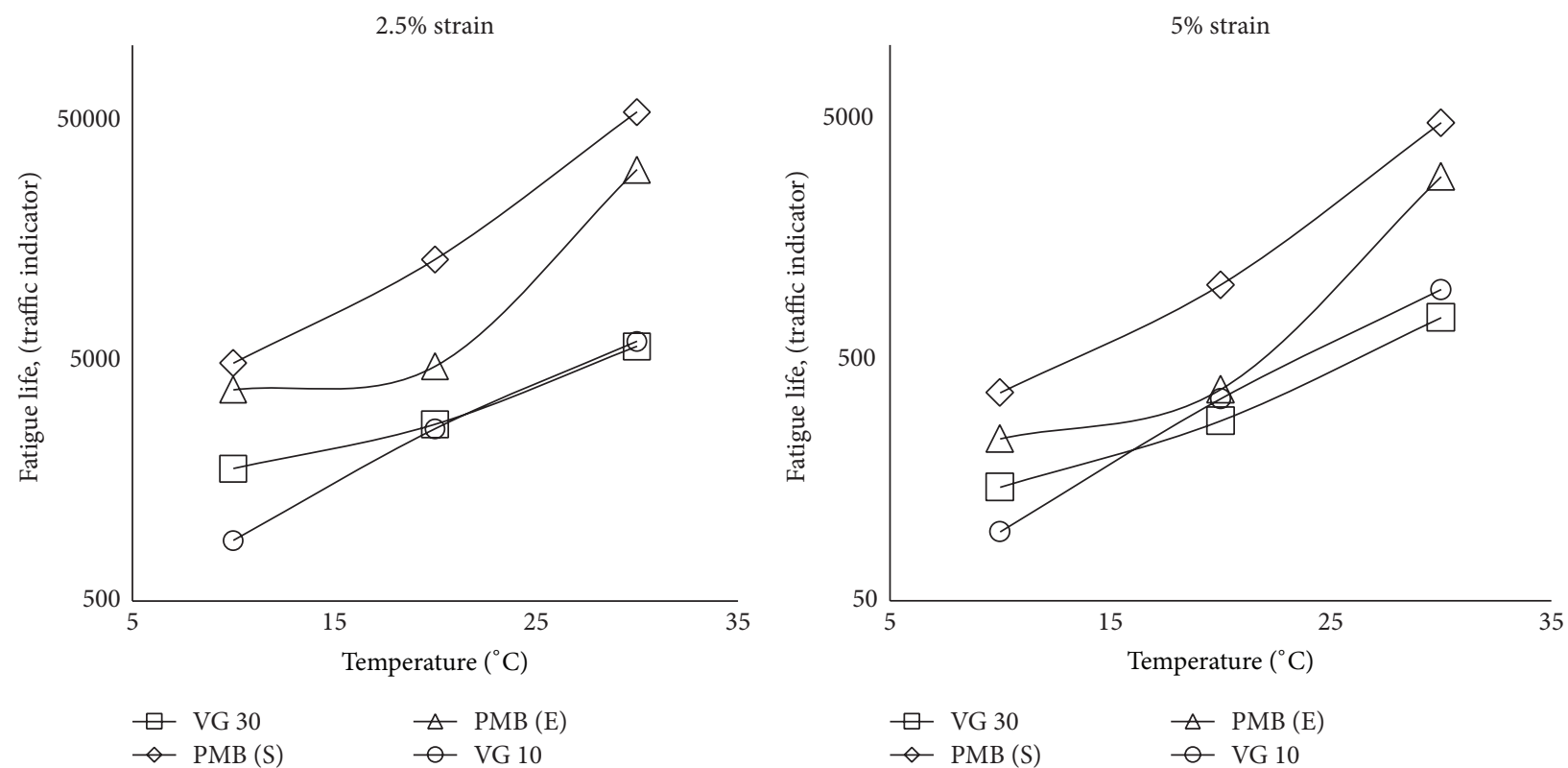

FIGURE 4: Variation of fatigue life with temperature at two different strain levels.

TABLE 4: Values of fatigue parameters $\alpha$ and $A$.

\begin{tabular}{|c|c|c|c|c|c|c|}
\hline \multirow{2}{*}{ Binders } & \multicolumn{3}{|c|}{$\alpha$} & \multicolumn{3}{|c|}{$A$} \\
\hline & $10^{\circ} \mathrm{C}$ & $20^{\circ} \mathrm{C}$ & $30^{\circ} \mathrm{C}$ & $10^{\circ} \mathrm{C}$ & $20^{\circ} \mathrm{C}$ & $30^{\circ} \mathrm{C}$ \\
\hline VG 10 & 1.6048405 & 1.4582551 & 0.3822351 & 16892.32 & 37431.015 & 65396.962 \\
\hline VG 30 & 1.7922338 & 1.6402502 & 0.3409223 & 47259.719 & 54534.01 & 83388.288 \\
\hline $\mathrm{PMB}(\mathrm{S})$ & 1.8680149 & 1.8391338 & 0.2876897 & 148400.75 & 378251.85 & 1279936.4 \\
\hline PMB (E) & 2.0018136 & 1.8236637 & 0.2922775 & 147129.68 & 132799.17 & 702093.28 \\
\hline
\end{tabular}

life increases with increase in temperature for all the binders. The increase in fatigue life with increase in temperature was the highest for VG 10, indicating higher temperature susceptibility.

4.2. Marshall Mix Results. Table 5 presents the result of the optimum binder content and the corresponding Marshall Mix parameters. The stability of mixes prepared with modified binders was higher than those prepared with conventional binders. Amongst different mixes, SMA had the lowest stability values attributed to higher VMA and binder content. The retained Marshall Stability values were found to be higher for mixes prepared with modified binders. Moreover, amongst all the mixes, SMA had the highest retained stability value. Two outcomes can be derived from this observation. First, the modified binders have lower temperature susceptibility and secondly higher binder content (as in SMA mixes) tends to increase the film thickness making the mix more durable and resistant to moisture damage.

4.3. Indirect Tensile Strength (ITS). Figure 5 presents the ITS results for the three types of mixes prepared using different binders. The results revealed that modified binders have higher values as compared to mixes prepared with conventional binders. Dense graded mixes such as BC displayed

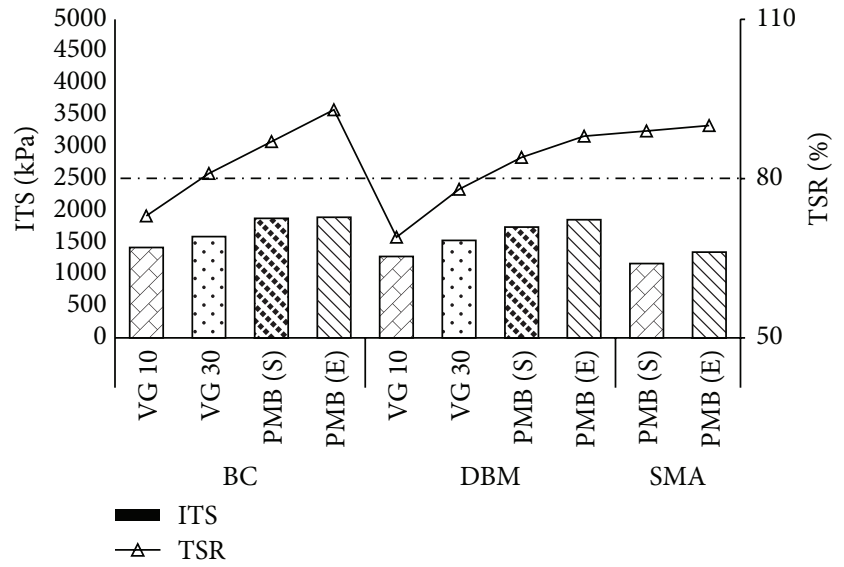

FIGURE 5: ITS values for different mixes.

higher values as compared to gap-graded SMA. Though the ITS values for BC and DBM mixes are higher than SMA, they will develop cracks due to lower binder content. It is hence necessary to determine the resistance to cracking for different mixes from repeated bending test. The TSR values were also plotted on the secondary axis. Modified binders were found to be least susceptible to moisture damage. The minimum 
400 microstrains
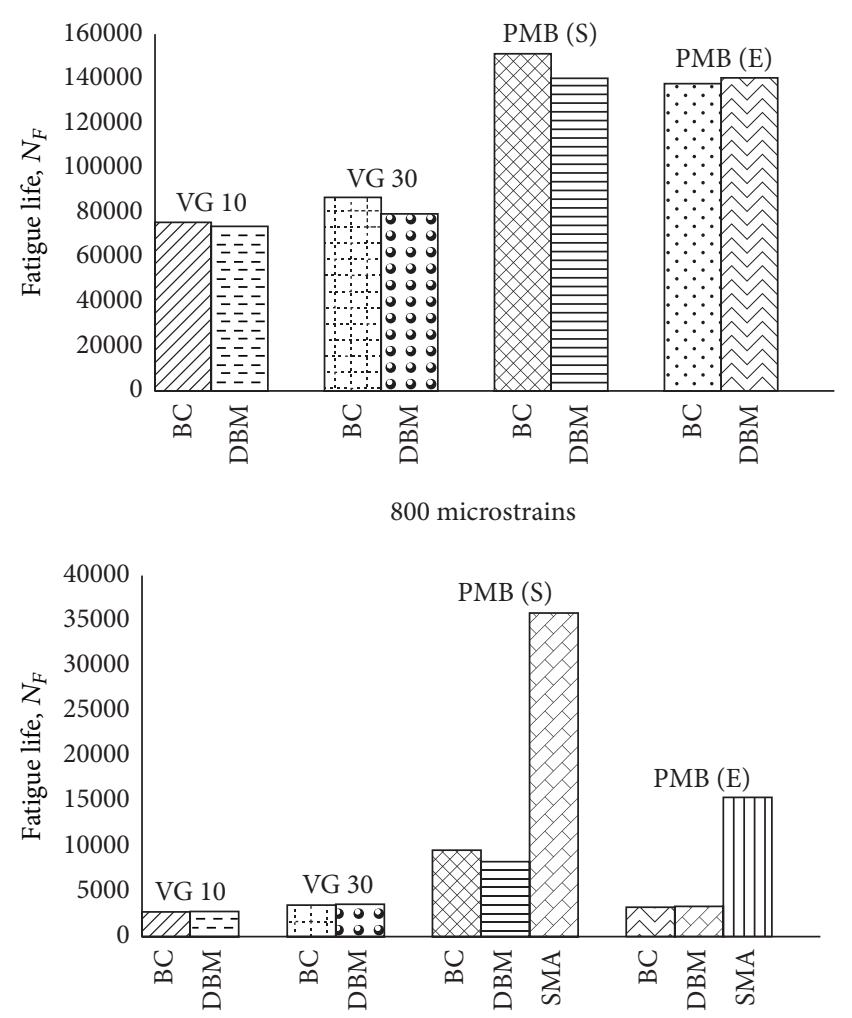

600 microstrains

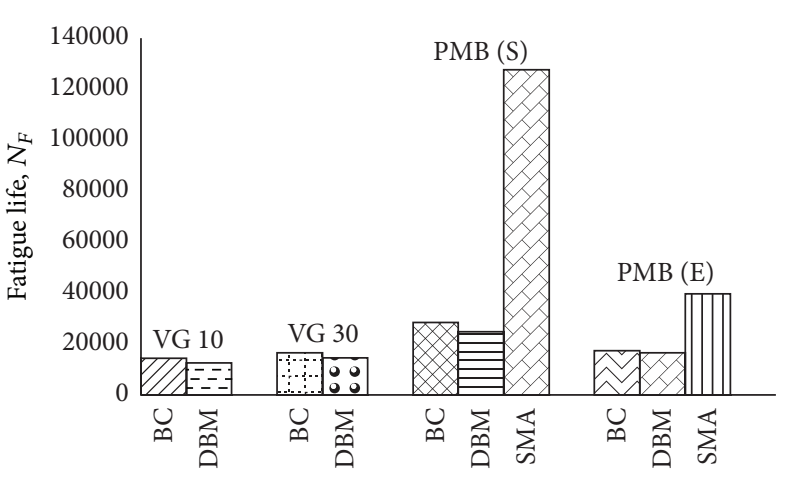

1000 microstrains

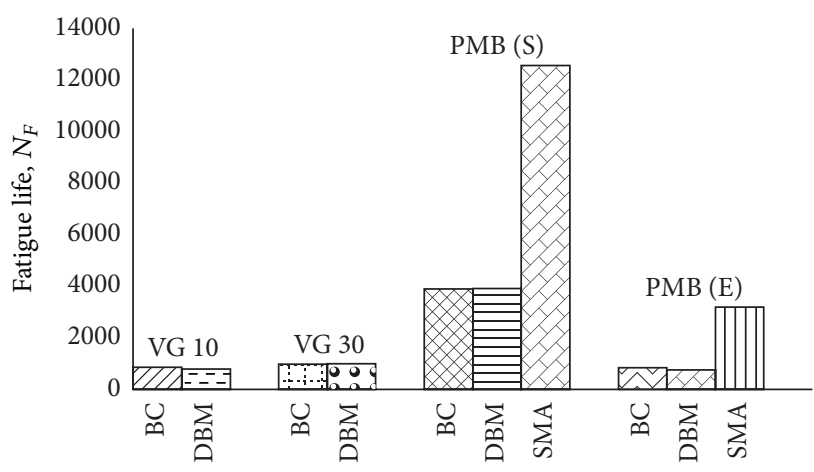

FIGURE 6: Fatigue life at different strain levels.

Table 5: Results of Marshall Mix design.

\begin{tabular}{lcccccccccc}
\hline \multirow{2}{*}{ Mix properties } & \multicolumn{4}{c}{ BC } & \multicolumn{4}{c}{ DBM } & \multicolumn{3}{c}{ SMA } \\
& VG 10 & VG 30 & PMB (S) & PMB (E) & VG 10 & VG 30 & PMB (S) & PMB (E) & PMB (S) & PMB (E) \\
\hline$G_{s b}$ & & & 2.712 & & & \multicolumn{2}{c}{2.712} & 2.71 \\
$G_{b}$ & 1.02 & 1.02 & 1.03 & 1.04 & 1.02 & 1.02 & 1.03 & 1.04 & 1.03 & 1.04 \\
$G_{m b}$ & 2.454 & 2.458 & 2.451 & 2.452 & 2.455 & 2.458 & 2.462 & 2.459 & 2.324 & 2.325 \\
$G_{m m}$ & 2.556 & 2.562 & 2.554 & 2.556 & 2.558 & 2.561 & 2.565 & 2.561 & 2.422 & 2.423 \\
OBC, \% & 4.9 & 5.1 & 5.1 & 5.1 & 4.7 & 4.7 & 4.8 & 4.8 & 6.7 & 6.7 \\
$V_{a}, \%$ & 3.99 & 4.06 & 4.03 & 4.07 & 4.03 & 4.02 & 4.02 & 3.98 & 4.05 & 4.04 \\
VMA, \% & 13.95 & 13.99 & 14.23 & 14.2 & 13.73 & 13.63 & 13.58 & 13.68 & 19.99 & 19.95 \\
VFB, \% & 71.39 & 70.98 & 71.67 & 71.34 & 70.68 & 70.48 & 70.42 & 70.89 & 79.76 & 79.73 \\
Stability, Kg & 1275 & 1359 & 1588 & 1675 & 1182 & 1278 & 1450 & 1570 & 970 & 1015 \\
Flow, mm & 3.1 & 2.9 & 3.2 & 3.4 & 3.6 & 3.4 & 3.1 & 3.1 & 3.8 & 3.7 \\
Marshall quotient & 4.11 & 4.68 & 4.96 & 4.92 & 3.28 & 3.75 & 4.67 & 5.06 & 2.55 & 2.74 \\
Retained Marshall Stability, \% & 62 & 67 & 79 & 82 & 67 & 66 & 80 & 85 & 95 \\
\hline
\end{tabular}

specification criteria of $80 \%$ TSR were not satisfied for mixes prepared with VG 10. For DBM, VG 30 also displayed slightly lower value than the minimum required. Hence, for these mixes, antistripping agent should be used to protect it from being vulnerable to moisture effects.

4.4. Fatigue Life from $4 P B B T$. Figure 6 presents the comparison of the fatigue life of different mixes for each binder type. The results of 200 microstrains are not shown because all the mixes exhibited fatigue life higher than $2 \times 10^{5}$ cycles. At
400 microstrains, SMA mixes prepared with PMB (S) and PMB (E) also had higher fatigue life. It was found that, at lower strain levels (<600 microstrains), mixes prepared with polymer modified binders exhibited higher fatigue life than those prepared using conventional binders. Amongst the polymer modified binders, PMB (S) gave superior results. As the strain level increased, the fatigue life of PMB (E) reduced drastically and was almost close to the behavior shown by conventional binders. PMB (S), on the other hand, displayed the best performance at all the strain levels. Amongst all 

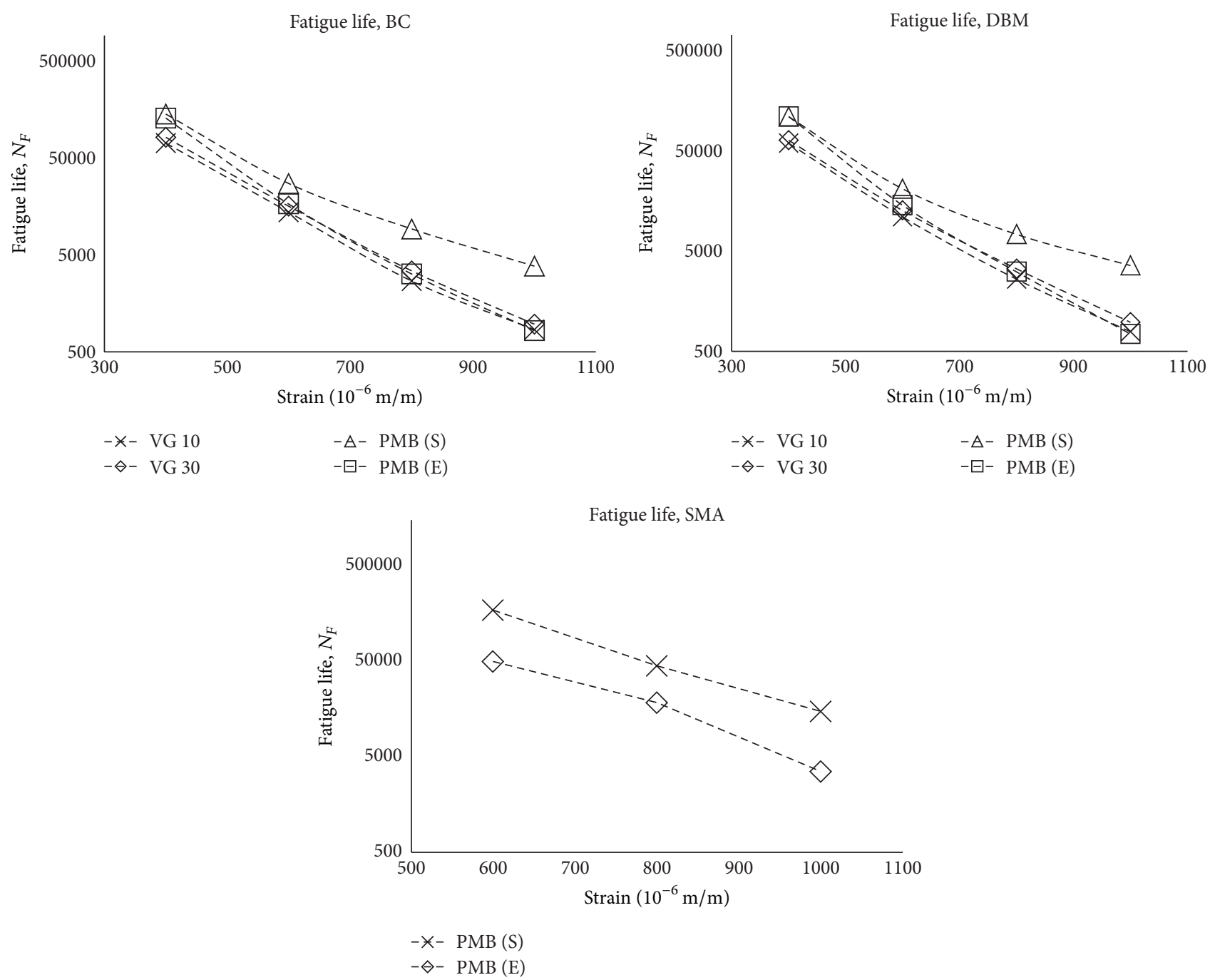

FIGURE 7: Fatigue life of different type of bituminous mixes.

the mixes, SMA had the highest fatigue life, which was almost 5 times the fatigue life of $\mathrm{BC}$ and DBM. This may be attributed to the volumetric of the bituminous mixture. SMA being a gap-graded mix has high VMA (17-22\%), which can accommodate ample amount of bitumen for a fixed air void content of $4 \%$. This increases the film thickness inside the mix, making the mix more durable to the induced strain.

Figure 7 illustrates the fatigue life as a function of strain. The slope of the curve indicates the sensitivity of the binders to the change in the magnitude of strain. PMB (E) showed highest susceptibility to this change while PMB (S) was found to be least susceptible. It was found that at lower strain levels $(\leq 400 \mu \mathrm{m})$ PMB (E) had fatigue life very close to PMB (S). But as the strain increased, the fatigue life of PMB (E) decreased very sharply. At higher strain amplitudes $(\geq 800 \mu \mathrm{m})$, the fatigue life of PMB (E) mixes was even lower than that of the mixes prepared using conventional binders. This behavior of PMB (E) may be explained as follows. In PMB (E), the crystalline nature of the polymer stiffens the binder inducing viscous behavior. At low strains, due to high stiffness, the binder can take higher number of load repetitions without any damage. But due to the rigid nature, it cannot be stretched to higher strain which will result in formation of cracks. On the other hand, in PMB (S), the polymers are cross-linked to a three-dimensional network. The polystyrene end-blocks impart strength while the butadiene mid-blocks impart exceptional elasticity. This makes the binder more flexible and increases its capability to resist higher strains.

4.5. Correlation of LAS and $4 P B B T$ Results. It was attempted to correlate the fatigue results of asphalt binders with the fatigue life of asphalt mixtures. Assuming that the strain in binder is about 50 times the strain in mixtures, four strain levels $(2,3,4$, and $5 \%)$ of LAS test were chosen corresponding to four similar strain levels $(400,600,800$, and 1000 microstrains) of 4PBBT. Plotting the results of the binders against the fatigue life of mixes, it can be seen from Figure 8 that linear correlation is achieved for all the mixes. For PMB (E) and PMB (S), the fatigue life for SMA is also shown. It can be seen that the slope for SMA deviates 

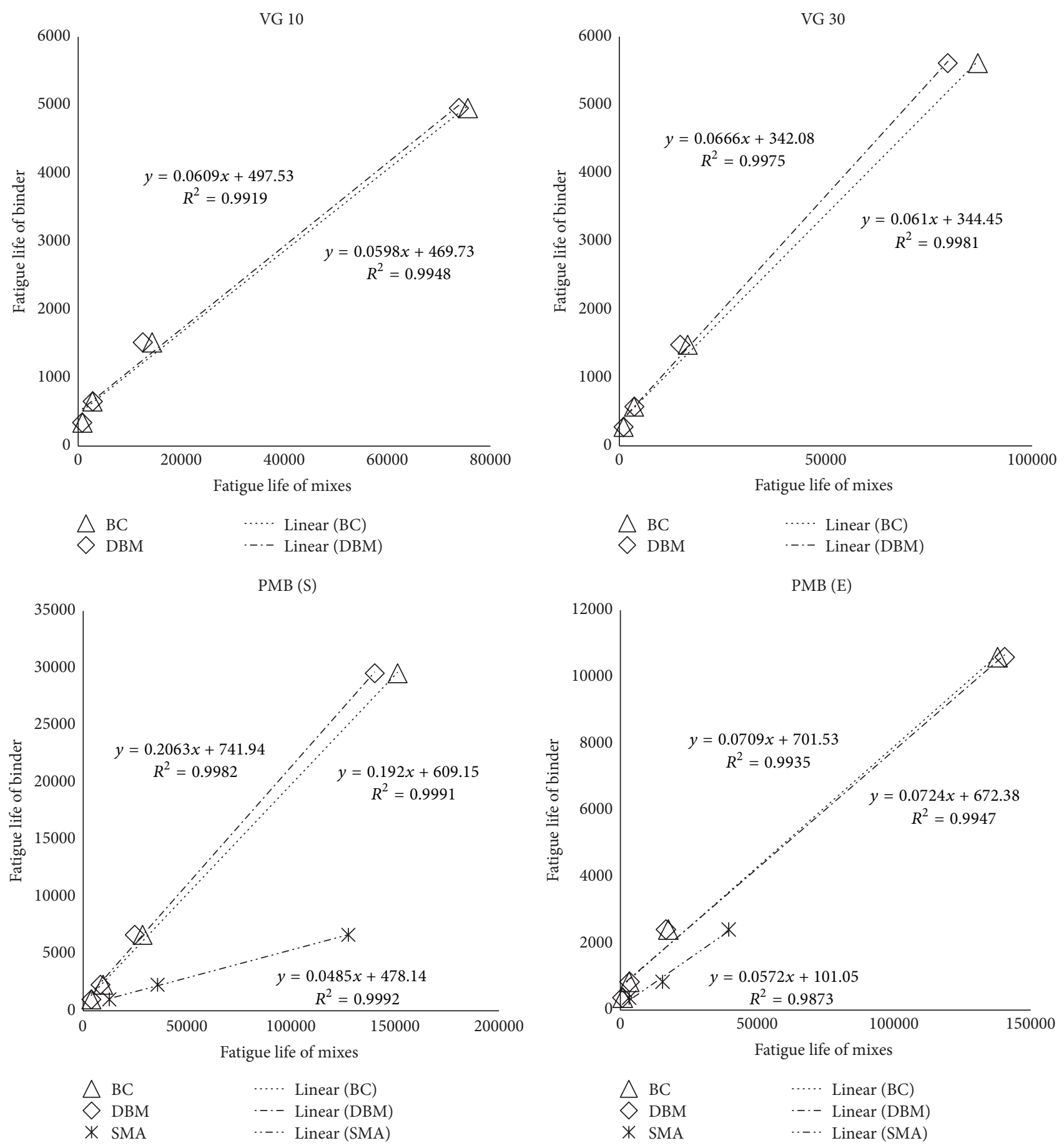

FIGURE 8: Correlation of fatigue life of asphalt binders and mixes.

considerably compared to that of $\mathrm{BC}$ and DBM. This may be attributed to the higher VMA for SMA mixes as compared to $\mathrm{BC}$ and DBM. The correlation equation however varies with the type of mix for each binder.

\section{Conclusions}

Based on the results of the experimental and analytical investigations on fatigue behavior of different unmodified and modified bituminous binders and mixes, the following conclusions have been drawn:

(1) LAS test was found to be more practical than the existing intermediate performance criteria of $G^{*} \cdot \sin \delta$. By LAS test, it was possible to evaluate the complex behavior of the binder at a wide range of loading levels. Elastomeric polymer modified binder (PMB (S)) displayed the highest fatigue life at all the test temperatures. PMB (E) was found to be susceptible 
to strain amplitudes at 10 and $20^{\circ} \mathrm{C}$ at which the performance degraded at higher strain levels. VG 10 and VG 30 had lower fatigue lives at lower strain amplitudes. But the rate of decrease in fatigue life with increase in strain level was lower than the modified binders. VG 10 had the lower strain susceptibility and gave better results than PMB (E) and VG 30 at higher strain amplitudes. However, at $30^{\circ} \mathrm{C}, \mathrm{PMB}(\mathrm{E})$ performed better than the conventional binders.

(2) The Marshall test results indicated higher stability for dense graded mixtures prepared with polymer modified bitumen. SMA mixes displayed lower stability values attributed to high VMA and increased binder content.

(3) The moisture susceptibility as shown by the retained Marshall Stability test was higher for conventional binders. The retained Marshall Stability values for SMA mixes were found to be higher than the dense graded mixes. This is attributable to the higher binder content which increases the film thickness making the mix water resistant. ITS values for BC and DBM were found to be higher than SMA. Mixes prepared with modified binders displayed higher strength values in comparison to viscosity graded binders. VG 10 did not satisfy the minimum TSR criteria required to satisfy the moisture susceptibility criteria.

(4) At lower strain levels, mixes prepared with polymer modified binders had higher fatigue life as compared to mixes prepared with conventional viscosity graded binders. At high strain amplitude, mixes prepared with $\mathrm{PMB}(\mathrm{E})$ gave poor performance in fatigue. The fatigue life PMB (E) mixes were even lower than the mixes prepared using conventional binders. This is attributed to the high strain sensitivity of $\mathrm{PMB}$ (E). PMB (S) on the other hand gave best results in comparison to other binders.

(5) Amongst all the mixes, SMA gave the best performance in fatigue. The fatigue life of SMA mixes was almost five times higher as compared to other bituminous mixtures. This is attributed to the high VMA percentage, which can accommodate large amount of binder for a fixed air void content. This increases the film thickness which reduces the stress and increases the durability.

(6) It was found that for similar strain levels the fatigue life of asphalt binders could be linearly correlated with the fatigue life of asphalt mixes. The correlation equation varies with the type of mix for each binder.

\section{Conflict of Interests}

The authors declare that there is no conflict of interests regarding the publication of this paper.

\section{References}

[1] E. Santagata, O. Baglieri, D. Dalmazzo, and L. Tsantilis, "Evaluation of the anti-rutting potential of polymer-modified binders by means of creep-recovery shear tests," Materials and Structures, vol. 46, no. 10, pp. 1673-1682, 2013.

[2] Y. Becker and M. P. Méndez, "Polymer modified asphalt," Visionary Technologies, vol. 9, pp. 39-50, 2001.

[3] F. Cardone, G. Ferrotti, F. Frigio, and F. Canestrari, "Influence of polymer modification on asphalt binder dynamic and steady flow viscosities," Construction and Building Materials, vol. 71, pp. 435-443, 2014.

[4] X. Lu, U. Isacsson, and J. Ekblad, "Rheological properties of SEBS, EVA and EBA polymer modified bitumens," Materials and Structures, vol. 32, no. 216, pp. 131-139, 1999.

[5] B. Sengoz and G. Isikyakar, "Evaluation of the properties and microstructure of SBS and EVA polymer modified bitumen," Construction and Building Materials, vol. 22, no. 9, pp. 18971905, 2008

[6] G. D. Airey, "Rheological evaluation of ethylene vinyl acetate polymer modified bitumens," Construction and Building Materials, vol. 16, no. 8, pp. 473-487, 2002.

[7] G. D. Airey, Rheological Characteristics of Polymer Modified and Aged Bitumens, University of Nottingham, Nottingham, UK, 1997.

[8] U. Isacsson and X. Lu, "Characterization of bitumens modified with SEBS, EVA and EBA polymers," Journal of Materials Science, vol. 34, no. 15, pp. 3737-3745, 1999.

[9] F. Zhou, W. Mogawer, H. Li, A. Andriescu, and A. Copeland, "Evaluation of fatigue tests for characterizing asphalt binders," Journal of Materials in Civil Engineering, vol. 25, no. 5, pp. 610617, 2013.

[10] C. M. Johnson, H. U. Bahia, and A. Coenen, "Comparison of bitumen fatigue testing procedures measured in shear and correlations with four-point bending mixture fatigue," in Proceedings of the 2nd Workshop on Four Point Bending, Pais, University of Minho, Guimarães, Portugal, 2009.

[11] C. M. Johnson, H. Bahia, and H. U. Wen, "Practical application of viscoelastic continuum damage theory to asphalt binder fatigue characterization," Journal of the Association of Asphalt Paving Technologists, vol. 78, pp. 597-638, 2009.

[12] C. Hintz, R. Velasquez, C. Johnson, and H. Bahia, "Modification and validation of linear amplitude sweep test for binder fatigue specification," Transportation Research Record, vol. 2207, pp. 99106, 2011.

[13] C. Hintz and H. Bahia, "Understanding mechanisms leading to asphalt binder fatigue in the dynamic shear rheometer," Road Materials and Pavement Design, vol. 14, supplement 2, pp. 231251, 2013.

[14] D. A. Anderson and T. W. Kennedy, "Development of SHRP binder specification," Journal of the Association of Asphalt Paving Technologists, vol. 62, pp. 481-507, 1993.

[15] H. Ziari, R. Babagoli, and A. Akbari, "Investigation of fatigue and rutting performance of hot mix asphalt mixtures prepared by bentonite-modified bitumen," Road Materials and Pavement Design, vol. 16, no. 1, pp. 101-118, 2015.

[16] H. Di Benedetto, C. de La Roche, H. Baaj, A. Pronk, and R. Lundström, "Fatigue of bituminous mixtures," Materials and Structures, vol. 37, no. 3, pp. 202-216, 2004.

[17] J. B. Sousa, J. C. Pais, M. Prates, R. Barros, P. Langlois, and A.-M. Leclerc, "Effect of aggregate gradation on fatigue life of asphalt 
concrete mixes," Transportation Research Record, vol. 1630, pp. 62-68, 1998.

[18] J. T. Harvey, J. A. Deacon, B. Tsai, and C. L. Monismith, "Fatigue performance of asphalt concrete mixes and its relationship to asphalt concrete pavement performance in California," Tech. Rep. RTA-65W485-2, Berkeley, Calif, USA, 1995.

[19] S. Adhikari, S. Shen, and Z. You, "Evaluation of fatigue models of hot-mix asphalt through laboratory testing," Transportation Research Record, vol. 2127, pp. 36-42, 2009.

[20] D. Bodin, C. de La Roche, and A. Chabot, "Prediction of bituminous mixes fatigue behavior during laboratory fatigue tests," in Proceedings of the 3rd Eurasphalt and Eurobitume Congress, pp. 1935-1945, Vienna, Austria, May 2004.

[21] M. E. Kutay, VECD (Visco-Elastic Continuum Damage): Stateof-the-Art Technique to Evaluate Fatigue Damage in Asphalt Pavements: History of the ViscoelasticContinuum Damage (VECD) Theory, Michigan State University, East Lansing, Mich, USA.

[22] A. A. A. Molenaar, "Prediction of fatigue cracking in asphalt pavements: do we follow the right approach?" Transportation Research Record, vol. 2001, pp. 155-162, 2007.

[23] Z. Suo and W. G. Wong, "Analysis of fatigue crack growth behavior in asphalt concrete material in wearing course," Construction and Building Materials, vol. 23, no. 1, pp. 462-468, 2009.

[24] P. J. Yoo and I. L. Al-Qadi, "A strain-controlled hot-mix asphalt fatigue model considering low and high cycles," International Journal of Pavement Engineering, vol. 11, no. 6, pp. 565-574, 2010.

[25] S. C. S. Tangella, J. Craus, J. A. Deacon, and C. L. Monismith, Summary Report on Fatigue Response of Asphalt Mixtures, 1990.

[26] C. Monismith, Fatigue Response of Asphalt-Aggregate Mixes, University of CAB, 1994.

[27] S. Shen, Dissipated energy concepts for HMA performance: fatigue and healing [ProQuest Diss Theses], University of Illinois at Urbana-Champaign, Champaign, Ill, USA, 2006.

[28] Y. H. Huang, Pavement Analysis and Design, Pearson Education, 2nd edition, 2010.

[29] F. Merusi, F. Giuliani, and G. Polacco, "Linear viscoelastic behaviour of asphalt binders modified with polymer/clay nanocomposites," Procedia-Social and Behavioral Sciences, vol. 53, pp. 335-345, 2012.

[30] V. O. Bulatović, V. Rek, and K. J. Marković, "Rheological properties and stability of ethylene vinyl acetate polymermodified bitumen," Polymer Engineering and Science, vol. 53, no. 11, pp. 2276-2283, 2013.

[31] T. Alataş and M. Yilmaz, "Effects of different polymers on mechanical properties of bituminous binders and hot mixtures," Construction and Building Materials, vol. 42, pp. 161-167, 2013.

[32] X. Lu and U. Isacsson, "Modification of road bitumens with thermoplastic polymers," Polymer Testing, vol. 20, no. 1, pp. 77$86,2000$.

[33] J. Zhu, B. Birgisson, and N. Kringos, "Polymer modification of bitumen: advances and challenges," European Polymer Journal, vol. 54, no. 1, pp. 18-38, 2014.

[34] G. D. Airey, "Rheological properties of styrene butadiene styrene polymer modified road bitumens," Fuel, vol. 82, no. 14, pp. 1709-1719, 2003.

[35] M. Ameri, A. Mansourian, and A. H. Sheikhmotevali, "Laboratory evaluation of ethylene vinyl acetate modified bitumens and mixtures based upon performance related parameters," Construction and Building Materials, vol. 40, pp. 438-447, 2013.
[36] N. Saboo and P. Kumar, "Optimum blending requirements for EVA modified binder," International Journal of Pavement Research and Technology, vol. 8, no. 3, pp. 172-178, 2015.

[37] IRC-SP79, Tentative Specifications for Stone Matrix Asphalt, Indian Roads Congress, New Delhi, India, 2008.

[38] AASHTO, "Estimating damage tolerance of asphalt binders using linear amplitude sweep," TP 101, 2014.

[39] S. W. Park, Y. R. Kim, and R. A. Schapery, "A viscoelastic continuum damage model and its application to uniaxial behavior of asphalt concrete," Mechanics of Materials, vol. 24, no. 4, pp. 241-255, 1996.

[40] E. Masad, N. Somadevan, H. U. Bahia, and S. Kose, "Modeling and experimental measurements of strain distribution in asphalt mixes," Journal of Transportation Engineering, vol. 127, no. 6, pp. 477-485, 2001. 


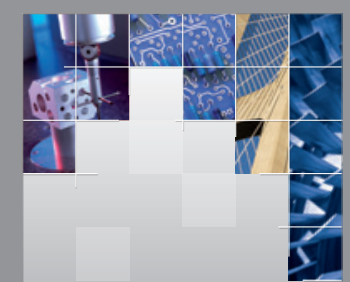

\section{Enfincering}
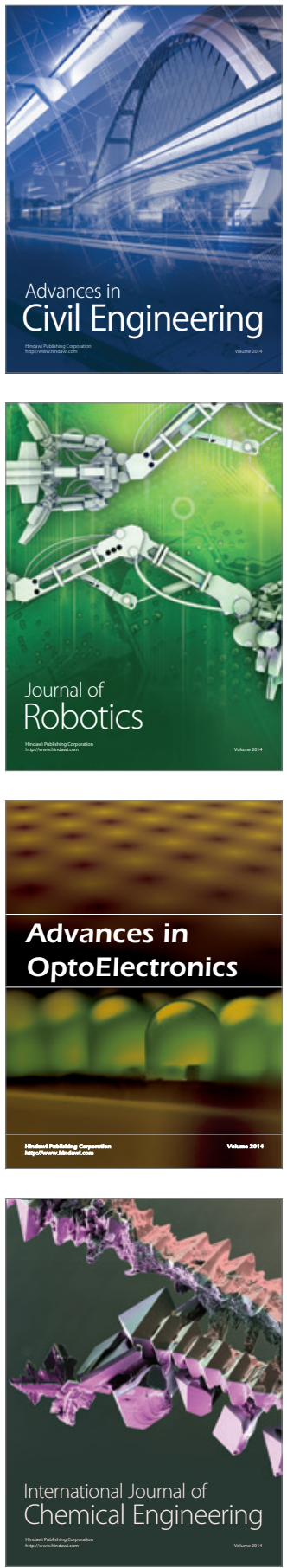

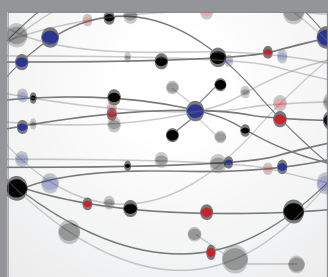

The Scientific World Journal

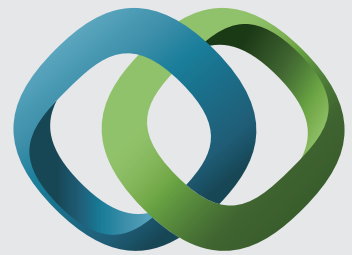

\section{Hindawi}

Submit your manuscripts at

http://www.hindawi.com
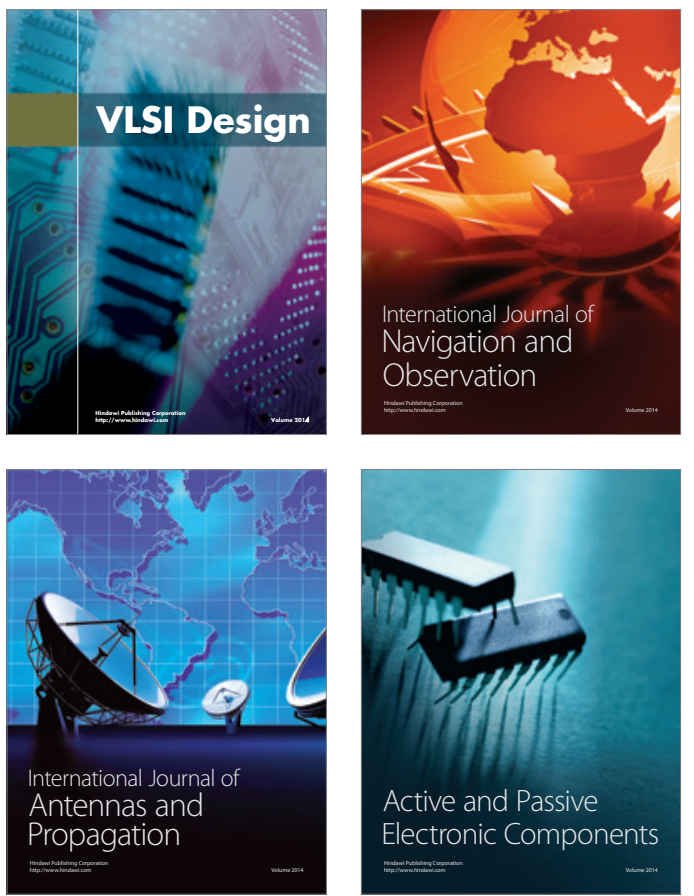
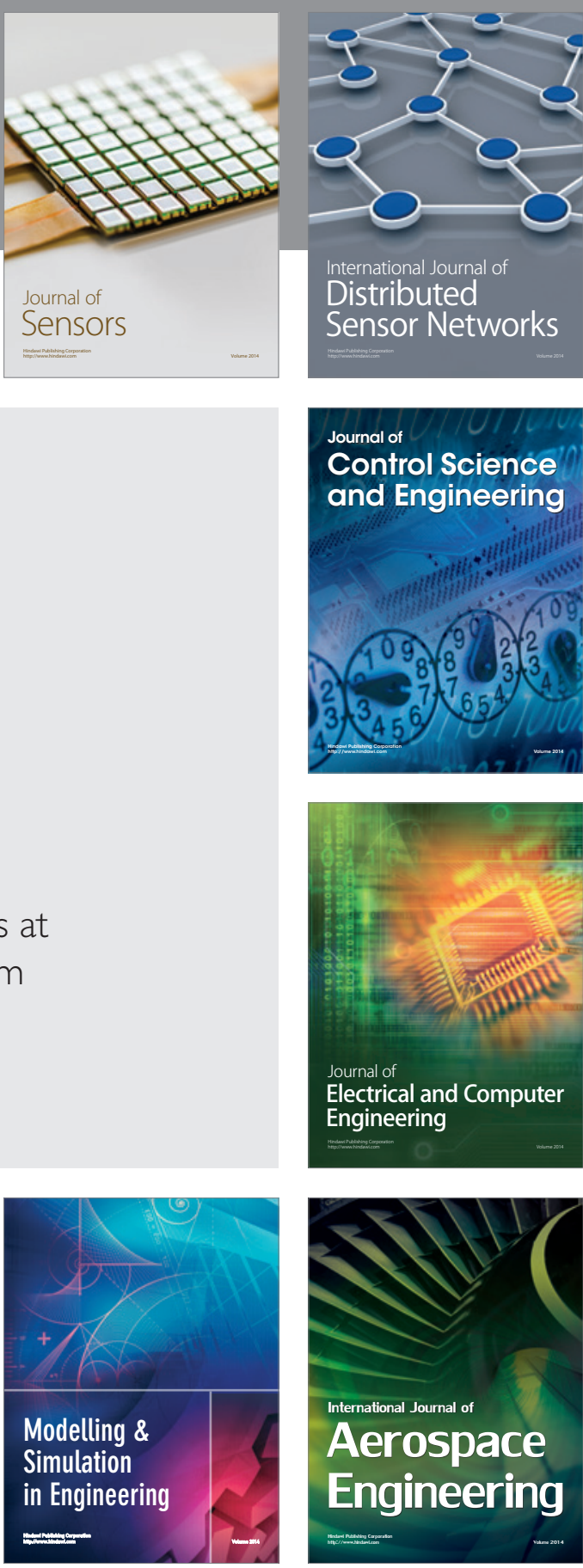

International Journal of

Distributed

Sensor Networks

Journal of

Control Science

and Engineering
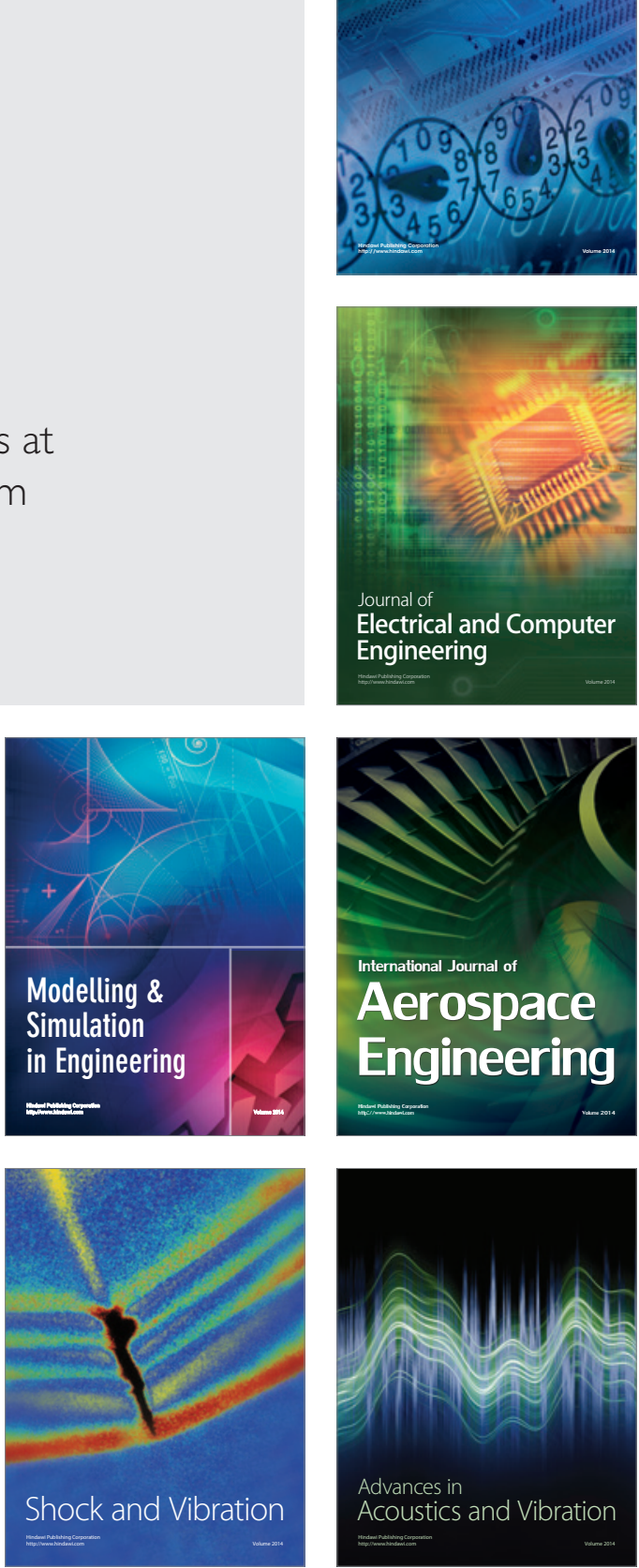